\title{
Article
}

\section{The case for collaborative learning: Introducing opportunities in the higher education setting}

\author{
Ridley, Neesha and Smith, Charlotte
}

Available at http://clok.uclan.ac.uk/17149/

Ridley, Neesha and Smith, Charlotte (2016) The case for collaborative learning: Introducing opportunities in the higher education setting. British Journal of Midwifery, 24 (4). pp. 282-285. ISSN 0969-4900

It is advisable to refer to the publisher's version if you intend to cite from the work. 10.12968/bjom.2016.24.4.282

For more information about UCLan's research in this area go to http://www.uclan.ac.uk/researchgroups/ and search for < name of research Group>.

For information about Research generally at UCLan please go to http://www.uclan.ac.uk/research/

All outputs in CLoK are protected by Intellectual Property Rights law, including Copyright law. Copyright, IPR and Moral Rights for the works on this site are retained by the individual authors and/or other copyright owners. Terms and conditions for use of this material are defined in the policies page.

\section{CLoK}

Central Lancashire online Knowledge www.clok.uclan.ac.uk

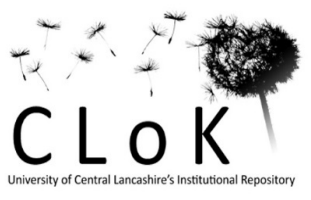




\section{The case for collaborative learning: Introducing opportunities in the higher education setting.}

Abstract: Public Health England (PHE) and the Department of Health (DH) (2015) have documented that parents are requesting consistent professional advice throughout pregnancy and the early weeks of life from midwives and health visitors. In addition to this, commissioners are increasingly seeking to integrate services to provide joined up care and improved health outcomes for parents and families (PHE, 2015 \& DH, 2015). This paper discusses the benefits of collaborative working, to both parents and healthcare professionals, together with the challenges faced by these professionals in the current climate. The paper continues to discuss the benefits of collaborative learning between the two disciplines within the higher education setting, with an example of a successful collaboration at the University of Central Lancashire (UCLan).

Parents want information and services around pregnancy and birth to be consistent and seamless, with services working together and with the family at the centre of service delivery (PHE \& DH, 2015). The 1001 Critical days (Leadsom, Field, Burstow \& Lucas, 2013) has documented that effective, individually designed service delivery can positively affect health outcomes. Midwives and health visitors, with their expertise on child and family health, are best placed to meet the needs of families during pregnancy and the early years (DH, 2009; Bennett, 2014; Brunton et al., 2014). However parents' experience of service delivery in the perinatal period often describes health visiting and midwifery as separate, non-communicative services (Donetto et al., 2013). There is plenty of evidence to support collaborative working between health care professionals, particularly where this will benefit the health outcomes for children and families (Gerrard et al, 2015). However, there is also evidence to demonstrate that in practice, collaboration between midwives, health visitors and other health care professionals does not always occur (Donetto et al, 2013; Calvert, 2015). 
Every contact with women and families should influence and maximise the health and wellbeing of the family (RCM, DH and PHE, 2013). Research has demonstrated that collaborative working in midwifery and health visiting, is both desirable and beneficial to women, children and families (Harris et al., 2015; RCM, 2011). From guiding vulnerable parents in their pregnancy to support with infant feeding and promotion of public health, collaborative working provides the best outcome for parents and healthcare professionals. There is a particular case for collaborative working between midwives and health visitors, for families with complex needs. Women with mental health needs, seek more support and often find a lack of collaboration between health care professionals, leading to poor relationships with the family (RCM, 2014). By working together with health care professionals and involving the family, sensitive information can be easily shared between disciplines, families feel well supported and are protected from having to repeat their stories to multiple health care professionals.

There is also a financial argument to support collaborative working. The public health budget is subject to $£ 200$ million cuts due to government priorities to address the current economic deficit faced by the UK (Buck, 2015). Current public health evidence places an emphasis on preventative strategies to reduce health inequalities (Marmot, 2010; Munro, 2011; PHE, 2014). As midwives and health visitors have prevention of ill health and promotion of safety and wellbeing at the very core of their practice (NMC, 2015), they have a duty to intervene together at an early opportunity to implement health protection and promotion and to avoid the costly duplication of services. Health visitors also have the privilege of ongoing contact with families until children enter school (DH, 2009). This provides an opportunity for developing a relationship with the family and other health care professionals and can also provide an opportunity for the promotion of public health, encouraging optimum health for the family. 
In the author's experience, collaborative working between midwives and health visitors is not facilitated within the educational curriculum. Furthermore, anecdotal evidence from student experience and from social media interaction suggest that collaborative working is somewhat inconsistent. Given the evidence supporting collaborative working between the disciplines, it seems that education is the place to introduce the theoretical concept in order for it to become normative and embedded within the role of practising health visitor and midwife

There are a number of possible reasons that joint visiting between midwives and health visitors is inconsistent in practice. The RCM (2015) report that England currently has a deficit of midwives and that 2600 more midwives are needed to support the number of births the country is experiencing. This has a significant impact, not only for midwives working in the NHS but for women and their families too. With postnatal care often dubbed the 'Cinderella service', postnatal care is often subject to financial cutbacks (Bird, 2014). Overlooking the crucial period beyond birth could be putting women at risk at their most vulnerable time. Without enough midwives to support women through this vulnerable time, women and families will not have the support needed to improve their health or seek advice about pregnancy and parenting. The situation for health visitors is also tenuous. The health visitor implementation plan (DH, 2011) which came to an end in 2015 , was responsible for the training and recruitment of 4200 health visitors. How feasible it will be for NHS midwives and health visitors to work in partnership following this remains to be seen. Furthermore, the commissioning of health visiting services will be at the discretion of the individual local authority which could lead to inconsistent service provision across the UK.

In the higher education setting, professions that work together in the NHS are often taught separately from each other. With universities expanding rapidly, this divide is growing and health care professionals no longer find themselves working as closely. It may be considered that the concept of midwifery and health visiting as two separate, unconnected services is therefore created before qualification. A longitudinal study by Pollard and Miers (2008) identified that when pre- 
registration health professionals learn together in the educational setting, students carry more positive concepts of collaborative, inter-professional relationships into practice following qualification than those educated separately. Furthermore, students who learn collaboratively report more confidence in their own communication and professional skills (Ruebling et al, 2014; Pollard \& Miers, 2008). It is the author's belief that higher education has a responsibility to create such opportunities for collaboration from the commencement of learning. Increased confidence, improved communication skills and knowledge of colleagues' roles can only be beneficial for students that are working to achieve optimal care for women and their families.

At UCLan, the School of Community Health and Midwifery have integrated collaborative working, within the first year of the undergraduate Midwifery programme. Collaborative working is taught during a theory block to the students and health care professionals from a variety of settings are invited to speak to the students about their role. Following this, students embark on practice placements on the postnatal ward - an area known for its multidisciplinary team working. The health visiting team were approached and were asked to give a presentation on the role of the health visitors, particularly within the maternity setting. The session was a straightforward introduction to the role of the health visitor and the students in return, were invited to talk about the role of the midwife - an informal session with the opportunity for lots of discussion. The response was overwhelmingly positive. All the collaborative working theory sessions were successful and this was measured by the feedback given by the students following the presentations. The students reported that they were inspired to learn about how midwives and other health care professionals could work together to provide the best care to women and families.

PHE and the DH (2015) have developed a document outlining the health visiting and midwifery partnership during pregnancy and the early years. It highlights the important visits and information that midwives and health visitors should offer to families, throughout the antenatal and postnatal period. The document outlines the roles of the two professions separately, but recommends that 
midwives and health visitors build on existing collaboration to maximise their roles (PHE \& DH, 2015). In education, we should be creating the platform for joint learning and working that can be built on in practice.

This year at UCLan we will build on the multidisciplinary platform which was introduced last year, and create opportunities for students of each profession to learn together and develop an understanding of each other's roles. It is our duty in education to promote a collaborative approach to learning. By learning and working together, midwives and health visitors can offer families consistent care and advice, avoid costly and time consuming duplication of work, develop confidence and expertise in their own skills and better understand the skills of their colleagues.

\section{$\underline{\text { References }}$}

Bennett, V. (2014) Keeping mum and baby well - partnership working between midwives and health visitors - Health Education East of England Health Visitor Programme Team London, Public Health England Accessed at: https://vivbennett.blog.gov.uk/2014/11/17/keeping-mum-and-baby-well/

Bird, H. (2014) A Cinderella story. Midwives magazine: Issue 1 2014. Accessed at:

https://www.rcm.org.uk/news-views-and-analysis/analysis/a-cinderella-story

Brunton G, Kneale D, Thomas J, Richardson, M. (2014) Community engagement for health via coalitions, collaborations and partnerships: a systematic review and meta-analysis. NICE report: Component 2

Buck, D. (2015) Cuts to public health spending: the falsest of false economies London, The King's Fund Accessed at: http://www.kingsfund.org.uk/blog/2015/08/cuts-public-health-spending-falsestfalse-economies 
Calvert, H. (2015) Time to Act for Better Collaboration with Health Visitors Online, Maternity Experience Accessed at: http://matexp.org.uk/feeding/time-to-act-for-better-collaboration-withhealth-visitors/

Department of Health (2009) Parents views on the maternity journey and early parenthood. Accessed at:

https://www.gov.uk/government/uploads/system/uploads/attachment data/file/215636/dh 12589 3.pdf

Department of Health (2011) The Health Visitor Implementation Plan 2011-2015 London, HMSO Department of Health (2013) The National Health Visitor Plan: progress to date and implementation 2013 onward London, HMSO Accessed at:

https://www.gov.uk/government/uploads/system/uploads/attachment data/file/208960/Impleme nting the Health Visitor Vision.pdf

Donetto, S; Malone, M; Hughes, J; Morrow, E; Cowley, S; and Maben, J (2013) Health Visiting : The Voice of Service Users London, Kings College London Accessed at:

https://www.kcl.ac.uk/nursing/research/nnru/publications/Reports/Voice-of-service-user-report$\underline{\text { July-2013-FINAL.pdf }}$

Gerrard, J. et al. (2011) A new vision for health visiting. Midwives Magazine, Issue 5 London, Royal College of Midwives Accessed at: https://www.rcm.org.uk/news-views-and-analysis/analysis/a-newvision-for-health-visiting

Harris S., Lewis K., Taylor C. (2015) Swansea Flying Start midwives and health visitors: Working together to tackle inequality. Journal of Health visiting. Accessed at: http://www.magonlinelibrary.com/doi/abs/10.12968/iohv.2015.3.11.584 
Leadsom A, Field F, Burstow, P \& Lucas, C (2013). The 1,001 critical days: the importance of the conception to age two period: a cross party manifesto. London: $\mathrm{DH}$

Marmot M. (2010) Fair Society, Healthy Lives: strategic Review of health Inequalities in England Post 2010. London: Marmot Review

Munro, E. (2011) The Munro Review of Child Protection : Final Report London, HMSO

https://www.gov.uk/government/uploads/system/uploads/attachment data/file/175391/Munro-

$\underline{\text { Review.pdf }}$

Nursing and Midwifery council (2015) The Code. Accessed at:

https://www.nmc.org.uk/standards/code/

Pollard, K.C. \& Miers, M. E (2008) From students to professionals: Results of a longitudinal study of attitudes to pre-qualifying collaborative learning and working in health and social care in the United Kingdom. Accessed at: http://www.tandfonline.com/doi/abs/10.1080/13561820802190483

Public Health England and Department of Health (2015) Health visiting and midwifery partnership pregnancy and early weeks London, Department of Health. Accessed at:

https://www.gov.uk/government/uploads/system/uploads/attachment data/file/465344/2903819

PHE Midwifery accessible.pdf

Public Health England (2014) From Evidence to Action: Opportunities to Protect and Improve the Nation's Health London, Crown Copyright Accessed at:

https://www.gov.uk/government/uploads/system/uploads/attachment data/file/366852/PHE Prior ities.pdf

Royal College of Midwives (2011) A new vision for health visiting. Accessed at: https://www.rcm.org.uk/news-views-and-analysis/analysis/a-new-vision-for-health-visiting 
Royal college of Midwives, Department of Health, Public Health England and NHS England (2013) The Midwifery public health contribution. Accessed at:

https://www.gov.uk/government/publications/the-midwifery-public-health-contribution

Royal college of Midwives (2014) Pressure points on maternal mental Health: Improving emotional wellbeing in postnatal care. Accessed at:

https://www.rcm.org.uk/sites/default/files/Pressure\%20Points\%20-\%20Mental\%20Health\%20-

\%20Final 0.pdf

Royal college of Midwives (2015) State of maternity services report. Accessed at:

https://www.rcm.org.uk/sites/default/files/RCM\%20State\%20of\%20Maternity\%20Services\%20Repo rt\%202015.pdf

Pollard, K. C., \& Miers, M. E. (2008). From students to professionals: Results of a longitudinal study of attitudes to pre-qualifying collaborative learning and working in health and social care in the United Kingdom. Journal of Interprofessional Care, 22(4), 399-416. doi:10.1080/13561820802190483

Ruebling, I., Pole, D., Breitbach, A. P., Frager, A., Kettenbach, G., Westhus, N., Carlson, J. (2014). A comparison of student attitudes and perceptions before and after an introductory interprofessional education experience. Journal of Interprofessional Care, 28(1), 23-27.

doi:10.3109/13561820.2013.829421 